\section{Angioimmunoblastic T-cell lymphoma presenting with an acute serologic Epstein-Barr virus profile}

\author{
Timothy Beer, ${ }^{1}$ Patrick Dorion ${ }^{2}$ \\ ${ }^{1}$ Department of General Internal Medicine \\ and ${ }^{2}$ Department of Hematopathology, \\ Geisinger Medical Center, Danville, PA, \\ USA
}

\section{Abstract}

Angioimmunoblastic T-cell lymphoma (AITL) is an aggressive peripheral T-cell lymphoma typically characterized by prominent lymphadenopathy and B-symptoms at the time of presentation, polyclonal hypergammaglobulinemia, autoimmune hemolysis and frequent but highly variable involvement of EpsteinBarr virus (EBV). Lymph node biopsy findings typically include effacement of nodal architecture, polymorphic infiltrate, atypical T-cells (usually $\mathrm{CD} 4+/ \mathrm{CD} 10+/ \mathrm{PD} 1+$ ) and prominent proliferations of high endothelial venules and follicular dendritic cells. However, this classic constellation of pathologic findings is often initially obscured by a prominence of $\mathrm{EBV}+\mathrm{B}$ immunoblasts with or without associated peripherally circulating EBV DNA. Here we document the first reported case of an acute serologic EBV profile (VCA-IgM) in a patient with AITL, and we recommend that clinicians maintain a high index of suspicion for AITL in the appropriate clinical scenario, irrespective of Epstein-Barr related findings.

\section{Case Report}

A 65-year-old man presented to the hospital with one month of worsening fatigue, fevers and night sweats. He had type II diabetes, hypertension and a remote history of multiple episodes of malaria while serving as a missionary in Papua New Guinea. On initial presentation, he was weak and febrile but had no palpable lymphadenopathy, hepatosplenomegaly or rash. Initial laboratory testing revealed anemia, thrombocytopenia, transaminitis and hyperbilirubinemia. Serum immunoelectrophoresis revealed a polyclonal hypergammaglobulinemia. Tests for malaria were negative by both microscopy and polymerase chain reaction. Blood and urine cultures were negative, as were tests for human immunodeficiency virus, viral hepatitis, Lyme and Ehrlichia. Computed tomography (CT) of the abdomen revealed splenomegaly. Bone marrow biopsy demonstrated a polyclonal plasmacytosis, but normal trilineage hematopoiesis. Despite negative testing, relapsed malaria became the working diagnosis and therapy was initiated with atovaquoneproguanil and doxycycline. His clinical condition improved markedly and he was discharged home.

One week later, the patient returned with fevers, tender palpable splenomegaly and an erythematous rash across his anterior chest. Epstein-Barr virus (EBV) testing was positive for IgG antibodies to viral capsid antigen (VCAIgG) and Epstein-Barr nuclear antigen (EBNAIgG), IgM antibodies to viral capsid antigen (VCA-IgM) and plasma EBV DNA to a level of $17,100 \mathrm{IU} / \mathrm{mL}$. He was discharged home with a plan of supportive care for a viral illness. However, the patient returned again, just one week later, with fevers and tender bilateral cervical and axillary lymphadenopathy. EBV testing was again positive for VCA-IgG, EBNA-IgG and VCA-IgM. Antibody to EBV early antigen (EA) was also positive. His EBV viral load had increased to $1,400,000 \mathrm{IU} / \mathrm{mL}$. Additional testing revealed a mixed cryoglobulinemia. He was administered high-dose steroids. EBV viral load was rechecked post-steroids and had decreased to $9000 \mathrm{IU} / \mathrm{mL}$. Bone marrow biopsy revealed a hypercellular marrow with diffuse patches of lymphoid infiltrates composed of dense clusters of EBV+ B-cells. Excisional biopsy of an enlarged right axillary lymph node revealed effacement of the nodal architecture and a mixture of large $\mathrm{EBV}+\mathrm{CD} 20+$ immunoblasts, plasma cells and histiocytes (Figure 1). Considered within the context of his EBV serology and viral load, his biopsy findings were felt to be compatible with an EBVassociated lymphoproliferative disorder. A trial of weekly rituximab was initiated.

One week after discharge, the patient's clinical condition appeared to be improving, his EBV viral load had decreased to $900 \mathrm{IU} / \mathrm{mL}$ and IgM-VCA had become equivocal. However, he returned to the hospital just two weeks later with fevers, night sweats and shortness of breath. He was now pancytopenic with a prominent hypereosinophilia. EBV viral load had increased slightly to $2100 \mathrm{IU} / \mathrm{mL}$. Repeat bone marrow biopsy revealed slightly hypercellular marrow with a few residual lymphoid infiltrates made up of heterogeneous T-cell populations but almost no B-cells and no EBV+ cells, felt to reflect rituximab therapeutic effect. He stabilized clinically and was discharged with plans to continue weekly rituximab treatments.

One day later, the patient returned with high fevers and shortness of breath. He was pancytopenic and now exhibited Coomb's positivity and a nonspecific cold agglutinin. EBV viral load had increased to $6700 \mathrm{IU} / \mathrm{mL}$. Excisional biopsy of an enlarged left axillary lymph node revealed
Correspondence: Timothy Coogan Beer Department of General Internal Medicine, Geisinger Medical Center, 100 North Academy Avenue, Danville, PA 17822, USA.

Tel.: + 1.310.804.2780

E-mail: tcbeer@geisinger.edu

Key words: Angioimmunoblastic t-cell lymphoma; Epstein-Barr virus.

Contributions: the authors contributed equally.

Conflict of interest: the authors declare no potential conflict of interest.

Received for publication: 1 March 2015. Accepted for publication: 18 May 2015.

This work is licensed under a Creative Commons Attribution NonCommercial 3.0 License (CC BYNC 3.0).

(C) Copyright T. Beer and P. Dorion, 2015

Licensee PAGEPress, Italy

Hematology Reports 2015; 7:5893

doi:10.4081/hr.2015.5893

complete effacement of the nodal architecture, a diffuse polymorphic infiltrate with a large number of atypical CD4+/CD10+/PD1+ T-cells, prominent vascular proliferation and a meshwork of follicular dendritic cells. A few scattered cells stained CD20+, but EBV staining was negative (Figure 2). Clonal rearrangements were detected in T-cell receptor genes. This constellation of findings was diagnostic for angioimmunoblastic T-cell lymphoma (AITL).

Over the next week, the patient's clinical condition worsened substantially and he developed profound refractory anemia and thrombocytopenia. His EBV viral load increased to $47,900 \mathrm{IU} / \mathrm{mL}$, while IgG-VCA and IgG-EBNA remained positive and IgM-VCA remained equivocal. Testing now revealed the presence of an anti-E antibody. He was administered Rituximab and started on daily high-dose steroids. Days later, his EBV viral load had come down to $6400 \mathrm{IU} / \mathrm{mL}$. However, his condition continued to worsen and he developed epistaxis, hemoptysis and preretinal hemorrhages. Chemotherapy was initiated with cyclophosphamide, dexamethasone, vincristine and doxorubicin (CHOP). He was discharged home with plans to continue chemotherapy as an outpatient. However, just two days later, he returned with persistent bleeding from his left axillary biopsy site. Bone marrow biopsy now revealed marked hypercellularity with diffuse dense atypical lymphoid infiltrates, composed predominately of the same atypical T-cells seen in his recent lymph node biopsy, admixed with plasma cells, eosinophils and occasional EBV+ B-cells. His chemotherapy regimen was intensified with the addition of etoposide (CHOEP). However, 
days later, he developed catastrophic pulmonary hemorrhage and expired.

\section{Discussion and Conclusions}

Angioimmunoblastic T-cell lymphoma (AITL) is a peripheral T-cell lymphoma characterized by lymphadenopathy and prominent systemic symptoms at initial presentation, peculiar hematologic laboratory abnormalities and a frequently observed but poorly-understood association with EBV.

In our review of 1249 reported cases of AITL (from 22 case series and 32 individual case reports), we found an average age at presentation of 63 years and a slight male predominance (59\%). Among case series with greater than 10 patients ( $\mathrm{n}=1194)$, common signs and symptoms included lymphadenopathy (86\%), B symptoms (69\%), splenomegaly (55\%) and rash (33\%). Characteristic laboratory abnormalities included elevated lactate dehydrogenase (69\%), elevated 2-microglobulinemia (67\%), anemia (53\%) and hypergammaglobulinemia (51\%). Additional laboratory abnormalities found in a significant minority of patients included Coomb's positivity (41\%), cryoglobulinemia (38\%), thrombocytopenia (27\%) and cold agglutinins (17\%). Bone marrow involvement was reported in $42 \%$ of patients, however, this statistic is somewhat limited by the wide variation in the points in the clinical course at which marrow biopsies were obtained, since the likelihood of bone marrow involvement seems to increase as the disease progresses. ${ }^{1-16}$

Angioimmunoblastic T-cell lymphoma has been consistently reported to have an association with EBV. In fact, EBV-positive Bimmunoblasts are detected in the lymph nodes and bone marrow in most cases of AITL. ${ }^{17}$ However, the nature of the relationship between EBV and AITL is unclear. Some authors argue that the presence of EBV reflects the profound immunodeficient state that AITL creates, while others argue that EBV itself drives the development of AITL. ${ }^{18,19}$ There have been several reports of EBV-associated B-cell proliferations in patients with AITL. ${ }^{20,21}$ In one large scale prospective series, Delfau-Larue et al. demonstrated that the presence of circulating EBV DNA is strongly correlated with the presence of circulating AITL tumor cells and that higher levels of peripheral EBV DNA at initial presentation is associated with poorer response to typical treatments. ${ }^{22}$ However, it seems that AITL has never been reported to present with an acute EBV serologic profile like that of our patient. Among the 1249 reported cases of AITL we reviewed, data on peripheral EBV DNA or serologic testing was reported in 44 cases (including 3 case series and 14 individual case reports). Among these, EBV DNA was detected in 48\% (13/27), VCA-IgG was detected in 89\% (31/35), EBNAIgG was detected in $81 \%(26 / 32)$, but detectable EBV-IgM was not reported in a single case (0/33) (Figure 3). ${ }^{22-35}$

Indeed, the lack of existing reports of EBVIgM in AITL, combined with the EBV+ B celldominated picture of the early bone marrow and lymph node biopsies, may have served to steer us away from the diagnosis of AITL in this case. The delay in diagnosis was certainly extended by the seeming responsiveness of our patient to rituximab. In the initial month or so, each dose of rituximab would seem to be followed by a temporary improvement in clinical status and reduction in EBV viral load. This pattern reinforced our mistaken suspicion that we were primarily dealing with an EBV-reactivation or EBV-associated proliferative disorder. The eradication of EBV+ B-immunoblasts, as evidenced on a subsequent bone marrow biopsy, provided further misguiding support that we were successfully battling an EBV-driven disorder. However, eventually, the patient's clinical status stopped improving with doses of rituximab, and at around the same time, his second lymph node biopsy revealed the telltale atypical CD4+/CD10+/PD1+ T-cells upon a prominent background of follicular dendritic cells and vascular proliferation characteristic of AITL. In retrospect, it is quite possible that the Rituximab was mainly responsible for the depletion of his $\mathrm{EBV}+\mathrm{B}$-cells, while the concomitantly administered high-dose steroids deserve most of the credit for his intermittent periods of symptomatic relief.

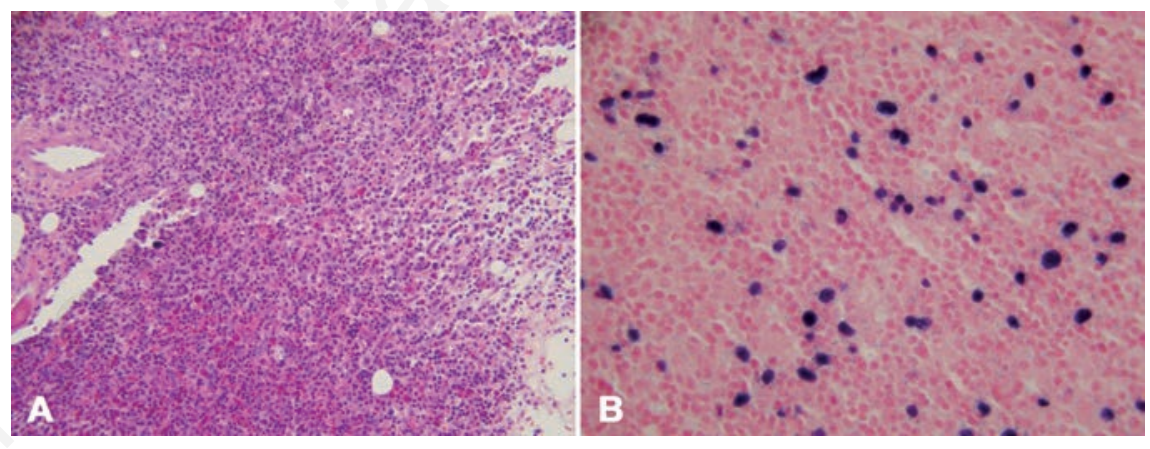

Figure 1. Bone marrow biopsy revealing hypercellular marrow with atypical lymphoid infiltrates (A) and left axillary lymph node biopsy with numerous lymphocytes staining positive for Epstein-Barr virus (B).
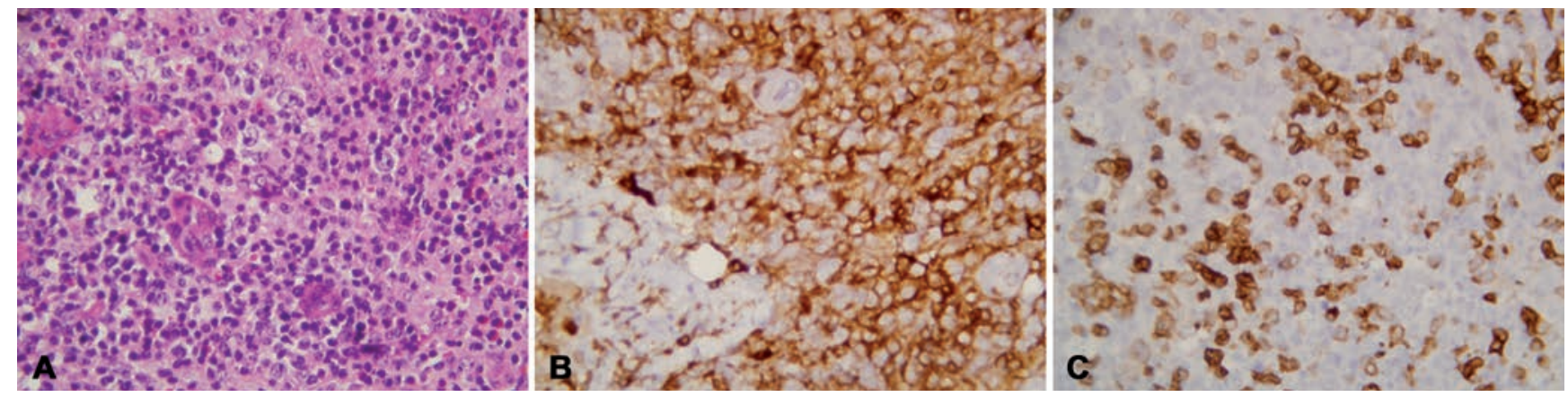

Figure 2. Lymph node biopsy revealing marked atypia and increased vascularity (A) with atypical T-cells staining positive for CD4 (B) and $\operatorname{CD} 10(\mathrm{C})$. 


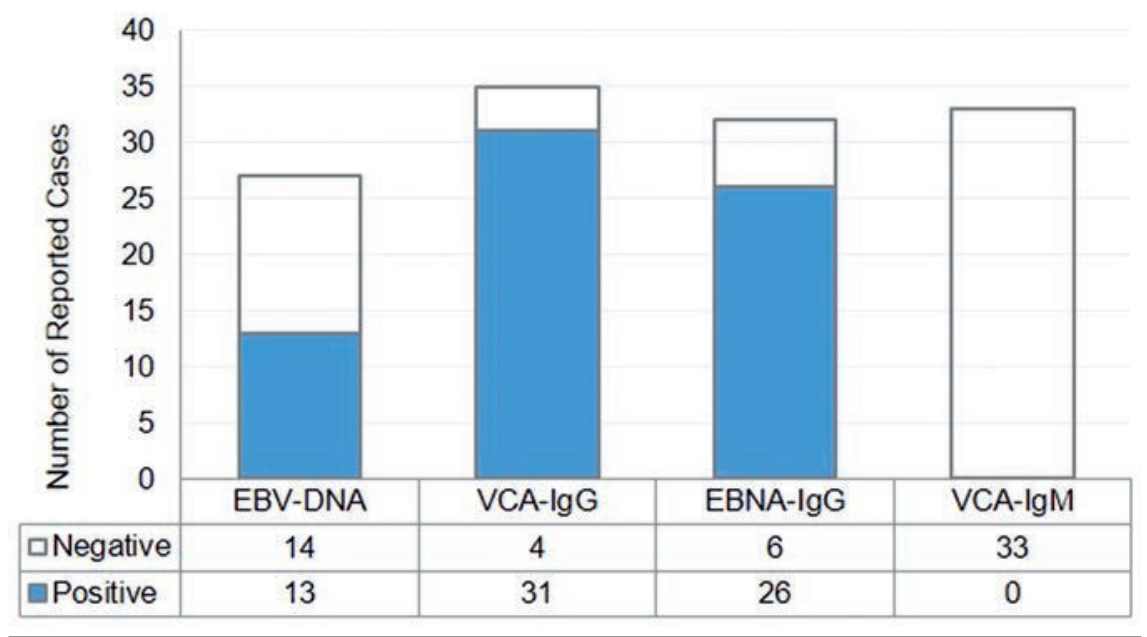

Figure 3. Peripheral Epstein-Barr virus data reported in cases of angioimmunoblastic Tcell lymphoma $(n=44)$.
This case provides a novel report of the presence of EBV-IgM in angioimmunoblastic T-cell lymphoma. However, its ultimate contribution to the body of literature should be to remind clinicians to strongly consider the diagnosis of AITL in any older adult presenting with Bsymptoms, lymphadenopathy, hypergammaglobulinemia, autoimmune phenomena and the presence of EBV in any capacity.

\section{References}

1. Attygalle A, Al-Jehani R, Diss TC, et al. Neoplastic T cells in angioimmunoblastic T-cell lymphoma express CD10. Blood 2002;99:627-33.

2. Baseggio L, Traverse-Glehen A, Berger F, et al. CD10 and ICOS expression by multiparametric flow cytometry in angioimmunoblastic T-cell lymphoma. Mod Pathol 2011;24:993-1003.

3. Federico M, Rudiger T, Bellei M, et al. Clinicopathologic characteristics of angioimmunoblastic T-cell lymphoma: Analysis of the international peripheral Tcell lymphoma project. J Clin Oncol 2013;31:240-6.

4. Ganesan TS, Dhaliwal HS, Dorreen MS, et al. Angio-immunoblastic lymphadenopathy: a clinical, immunological and molecular study. Br J Cancer 1987;55:437-42.

5. Lachenal F, Berger F, Ghesquieres $\mathrm{H}$, et al. Angioimmunoblastic T-cell lymphoma: clinical and laboratory features at diagnosis in 77 patients. Medicine (Baltimore) 2007;86:282-92.

6. Lee SS, Rudiger T, Odenwald $\mathrm{T}$, et al. Angioimmunoblastic T cell lymphoma is derived from mature T-helper cells with varying expression and loss of detectable CD4. Int J Cancer 2003;103:12-20.

7. Liang PI, Chang ST, Lin MY, et al. Angioimmunoblastic T-cell lymphoma in taiwan shows a frequent gain of ITK gene. Int J Clin Exp Pathol 2014;7:6097-107.

8. Lin HN, Liu CY, Hong YC, et al. Clinical features and prognostic factors of angioimmunoblastic T-cell lymphoma in Taiwan: a single-institution experience. Leuk Lymphoma 2010;51:2208-14.

9. Mourad N, Mounier N, Briere J, et al. Clinical, biologic, and pathologic features in 157 patients with angioimmunoblastic T-cell lymphoma treated within the groupe d'etude des lymphomes de l'adulte (GELA) trials. Blood 2008;111:4463-70.

10. Ohsaka A, Saito K, Sakai T, et al. Clinicopathologic and therapeutic aspects of angioimmunoblastic lymphadenopathyrelated lesions. Cancer 1992;69:1259-67.

11. Park BB, Ryoo BY, Lee JH, et al. Clinical features and treatment outcomes of angioimmunoblastic T-cell lymphoma. Leuk Lymphoma 2007;48:716-22.

12. Pautier P, Devidas A, Delmer A, et al. Angioimmunoblastic-like T-cell non hodgkin's lymphoma: outcome after chemotherapy in 33 patients and review of the literature. Leuk Lymphoma 1999;32: 545-52.

13. Siegert W, Nerl C, Agthe A, et al. Angioimmunoblastic lymphadenopathy (AILD)-type T-cell lymphoma: prognostic impact of clinical observations and laboratory findings at presentation. The Kiel Lymphoma Study Group. Ann Oncol 1995; 6:659-64.

14. Tokunaga T, Shimada K, Yamamoto K, et al. Retrospective analysis of prognostic factors for angioimmunoblastic T-cell lym- phoma: a multicenter cooperative study in japan. Blood. 2012;11):2837-43.

15. Yoon GS, Choi YK, Bak H, et al. Angioimmunoblastic T cell lymphomas: frequent cutaneous skin lesions and absence of human herpes viruses. Ann Dermatol 2009;21:1-5.

16. Zhang C, Wang XP, Zheng W, et al. [Angioimmunoblastic $\mathrm{T}$ cell lymphoma: clinical analysis of 42 cases ]. Zhonghua Yi Xue Za Zhi 2013;93:3671-4. [Article in Chinese]

17. Zhou Y, Attygalle AD, Chuang SS, et al. Angioimmunoblastic T-cell lymphoma: Histological progression associates with EBV and HHV6B viral load. Br J Haematol 2007;138:44-53.

18. Huang J, Zhang PH, Gao YH, Qiu LG. Sequential development of diffuse large Bcell lymphoma in a patient with angioimmunoblastic T-cell lymphoma. Diagn Cytopathol 2012;40:346-51.

19. Zhou Y, Attygalle AD, Chuang SS, et al. Angioimmunoblastic T-cell lymphoma: histological progression associates with EBV and HHV6B viral load. Br J Haematol 2007; 138:44-53.

20. Lome-Maldonado C, Canioni D, Hermine 0, et al. Angio-immunoblastic T cell lymphoma (AILD-TL) rich in large B cells and associated with epstein-barr virus infection. A different subtype of AILD-TL? Leukemia 2002;16:2134-41.

21. Tan BT, Warnke RA, Arber DA. The frequency of B- and T-cell gene rearrangements and epstein-barr virus in T-cell lymphomas: a comparison between angioimmunoblastic T-cell lymphoma and peripheral T-cell lymphoma, unspecified with and without associated B-cell proliferations. J Mol Diagn 2006;8:466-75.

22. Delfau-Larue MH, de Leval L, Joly B, et al. Targeting intratumoral B cells with rituximab in addition to CHOP in angioimmunoblastic T-cell lymphoma. A clinicobiological study of the GELA. Haematologica 2012;97:1594-602.

23. Anagnostopoulos I, Hummel M, Finn T, et al. Heterogeneous epstein-barr virus infection patterns in peripheral T-cell lymphoma of angioimmunoblastic lymphadenopathy type. Blood 1992;80:1804-12.

24. Battegay M, Berger C, Rochlitz C, et al. Epstein-barr virus load correlating with clinical manifestation and treatment response in a patient with angioimmunoblastic T-cell lymphoma. Antivir Ther 2004;9:453-9.

25. Choi JH, Oh YH, Park IK. A case of pure red cell aplasia associated with angioimmunoblastic T-cell lymphoma. Cancer Res Treat 2010;42:115-7.

26. Fabbri A, Cencini E, Pietrini A, et al. Impressive activity of lenalidomide 
monotherapy in refractory angioimmunoblastic T-cell lymphoma: report of a case with long-term follow-up. Hematol Oncol 2013;31:213-7.

27. Hatanaka K, Miyagishima T, Kamata T, et al. [Occurrence of angioimmunoblastic Tcell lymphoma six months after onset of lyme disease]. Rinsho Ketsueki 2000;41: 1273-6. [Article in Japanese]

28. Humeniuk MS, Liang JJ, Howard M, Inwards DJ. Spontaneous complete remission of angioimmunoblastic T-cell lymphoma. Proc (Bayl Univ Med Cent) 2014; 27:242-5.

29. Huppmann AR, Roullet MR, Raffeld M,
Jaffe ES. Angioimmunoblastic T-cell lymphoma partially obscured by an epsteinbarr virus-negative clonal plasma cell proliferation. J Clin Oncol 2013;31:e28-30.

30. Iqbal MH, Smith PR, Bande S. Chylothorax due to angioimmunoblastic T-cell lymphoma. Intern Med J 2009;39:67-8.

31. Ishiyama T, Watanabe K, Akimoto Y, et al. Circulating abnormal cells detected in a patient with immunoblastic lymphadenopathy. Intern Med 1993;32:455-8.

32. Kanzaki Y, Eura M, Chikamatsu K, et al. Angioimmunoblastic lymphadenopathylike T-cell lymphoma. A case report and immunologic study. Auris Nasus Larynx 1997;24:199-206.

33. Lachenal F, Berger F, Cimarelli S, et al. Primary cerebral angioimmunoblastic Tcell lymphoma. J Clin Oncol 2013;31:e64-8.

34. Nagoshi H, Kuroda J, Kobayashi T, et al. Clinical manifestation of angioimmunoblastic T-cell lymphoma with exuberant plasmacytosis. Int J Hematol 2013;98: 366-74.

35. Togashi M, Wakui H, Kodama K, et al. Angioimmunoblastic T-cell lymphoma and membranous nephropathy: a still unreported association. Clin Exp Nephrol 2010; 14:288-93. 